\title{
Performance of a Supersonic Model Combustor using Vaporized Kerosene Injection
}

\author{
Xuejun Fan ${ }^{*}$, Gong Yu ${ }^{* *}$, JianGuo. $\mathrm{Li}^{\dagger}$ and Xinyu. Zhang ${ }^{\ddagger}$, \\ Institute of Mechanics, Chinese Academy of Sciences \\ Beijing, 100080, P. R. China \\ Chih-Jen Sung ${ }^{\S}$ \\ Department of Mechanical and Aerospace Engineering \\ Case Westem Reserve University, Cleveland, OH 44106, USA
}

\begin{abstract}
Characteristics of supersonic combustion by injecting kerosene vapor into a Mach 2.5 crossflow at $v$ arious preheat temperatures and pressures were investigated experimentally. A two-stage heating system has been designed and tested, which can prepare heated kerosene of $0.8 \mathrm{~kg}$ up to $820 \mathrm{~K}$ at pressure of $5.5 \mathrm{MPa}$ with minimum/negligible fuel coking. In order to simulate the thermophysical properties of kerosene over a wide range of thermodynamic conditions, a three-component surrogate that matches the compound class of the parent fuel was employed. The flow rate of kerosene vapor was calibrated using a sonic nozzle. Computed flow rates using the surrogate fuel are in agreement with the experimental data. Kerosene jets at various preheat temperatures injecting into both quiescent environment and Mach 2.5 crossflow were visualized. It was found that at injection pressure of $4 \mathrm{MPa}$ and preheat temperature of $550 \mathrm{~K}$ the kerosene jet was completely in vapor phase, while keeping almost the same penetration depth as compared to the liquid kerosene injection. Supersonic combustion tests were also carried out to compare the combustor performance for the cases of vaporized kerosene injection, liquid kerosene injection, and effervescent atomization with hydrogen barbotage, under the similar stagnation conditions. Experimental results demonstrated that the use of vaporized kerosene injection leads to better combustor performance. Further parametric study on vaporized kerosene injection in a supersonic model combustor is needed to assess the combustion efficiency as well as to identify the controlling mechanism for the overall combustion enhancement..
\end{abstract}

\section{Introduction}

In practical hydrocarbon-fueled scramjet operations, liquid fuel can be used to cool down the engine flow path and absorb a part of heat imposed by the flight environment. It is therefore anticipated that the fuel temperature would vary with the different states of the flight mission. In the early flight stage, since the amount of heat absorbed by the fuel is minimal, the liquid hydrocarbon fuel would remain in the liquid state. As the flight speed increases beyond a certain value, the fuel temperature may be greater than the corresponding boiling point, leading to fuel vapor entering the combustor. As such, an optimized supersonic hydrocarbon-fueled combustor needs to account for both liquid fuel and vaporized fuel injection modes.

In terms of liquid hydrocarbon injection, our previous investigation ${ }^{[1]}$ has shown that a higher level of atomization can be achieved by using effervescent atomization, which can further promote the overall burning in a supersonic airflow. For situations under which the liquid fuel turns into gas phase by absorbing sufficient heat, it is unclear $a$ priori how the phase change of the hydrocarbon fuel affects the performance of a supersonic combustor.

Recognizing that for the successful operation of a liquid hydrocarbon-fueled scramjet the system residence time has to be sufficiently large to allow for liquid fuel vaporization and the initiation of chemical reactions, one apparent benefit utilizing the vaporized fuel injection is to bypass the atomization processes. In addition to eliminating the fuel vaporization time, fuel vapor of elevated temperature is expected to shorten the ignition delay

\footnotetext{
*Associate Professor, Institute of Mechanics, Chinese Academy Sciences, 15 Zhongguancun Road, Haidian District, Beijing, China 100080; xfancitimech acicn

"Professor, Institute of Mechanics, yugongaimech.ac.cn. Member AIAA.

${ }^{\dagger}$ Professor, Institute of Mechanics, jgli aimech.ac.cn. Member AIAA.

"Professor, Institute of Mechanics, changxy(aimech.ac cn. Member AIAA.

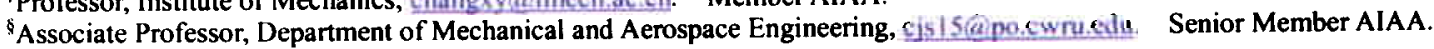

Copyright $\cong 2004$ by the authors. Published by the American Institute of Aeronautics and Astronautics Inc. with permission. 


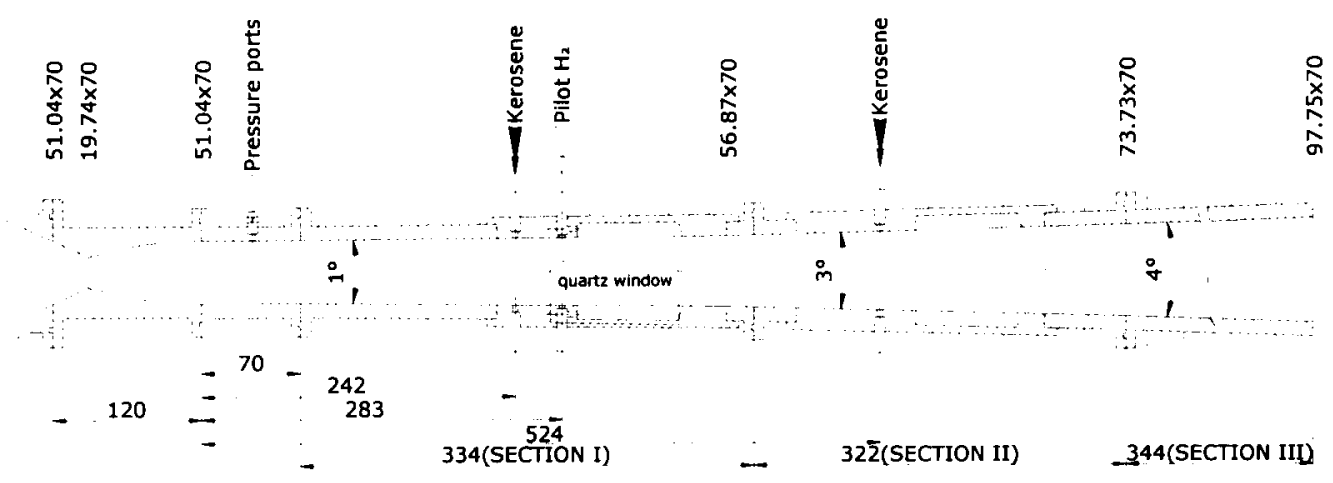

Figure 1 Schematic of kerosene/pilot hydrogen supersonic model combustor. All length dimensions are in mm.

time as well as to enhance the overall burning intensity. This would also in turn expand the combustion stability range by promoting self-ignition and extending the extinction limits, thereby facilitating flame stabilization. However, experimental investigation involving the use of vaporized hydrocarbon in a supersonic model combustor with flameholder cavities is meager. Therefore, the present study aims to extend our previous endeavors on liquid kerosene combustion in supersonic crossflows to assess the combustor performance with vaporized kerosene injection through systematic experimental characterizations. Our special emphasis is also on the performance comparison of vaporized fuel injection versus liquid fuel injection with and without effervescent atomization.

In the following, we shall first describe our test facility. In particular, the design of the heating and delivery system for kerosene fuel will be detailed. Moreover, the procedure of calibrating the flow rate of high-pressure kerosene vapor, which is a key issue in present investigation, will be outlined. In order to facilitate the future modeling of kerosene combustion, a three-species surrogate is chosen. Numerical simulations on the properties of the model fuel and the issues related to supercritical states will then be presented and discussed. With the simulated surrogate properties, the measured flow rate of kerosene vapor will be compared with the computed value. Subsequently, the behavior of heated kerosene jet plume will be explored by using direct photograph and Schlieren images in quiescent atmosphere and Mach 2.5 crossflow, respectively. The experiment results of vaporized kerosene injecting into a supersonic model combustor will also be presented and compared with the cases with liquid fuel injection and effervescent atomization with hydrogen barbotage.
Test Facility

\section{Facility Descriptions}

The Mach 2.5 test facility consisted of a vitiated air supply system, a multi-purpose supersonic combustor, and kerosene delivery and heating system. The system operation, control, and data acquisitions were accomplished with a computer. The system was capable of supplying heated air at the stagnation temperature of $800-2100 \mathrm{~K}$ and stagnation pressure of 0.7-1.3 $\mathrm{MPa}$. The supersonic combustor had an entrance cross-section area of 51 $\mathrm{mm} \times 70 \mathrm{~mm}$. As shown in Fig. 1, the combustor was comprised of three sections, namely one nearly constant area section and two divergent sections with total length of $1070 \mathrm{~mm}$.

Interchangeable integrated fuel injector and flameholder cavity modules with different configurations were used for supersonic combustion experiments. Each cavity was of $12 \mathrm{~mm}$ in depth and of 45 degrees in aft ramp angle. Both kerosene and pilot hydrogen were injected normally to the airflow through the cavity module pair shown in Fig. 1. In each module, there were five orifices of $0.9 \mathrm{~mm}$ diameter designed for vaporized kerosene as well as five orifices of $1.0 \mathrm{~mm}$ diameter for pilot hydrogen.

For some visualization experiments of spray structure of non-reacting kerosene jets in supersonic crossflow, the cavity flameholder was replaced by a flat plate module with only one injection orifice of $0.8 \mathrm{~mm}$. For light access and observation, a pair of quartz windows, each was $46 \mathrm{~mm}$ in height and 124 $\mathrm{mm}$ in length, were installed on both sides of the combustor near the location of cavity module.

The entire test facility was mounted upright on a platform and can be translated laterally and vertically. It usually takes approximately 2.5 seconds to establish a steady Mach 2.5 airflow and a typical run lasts 7 seconds. 


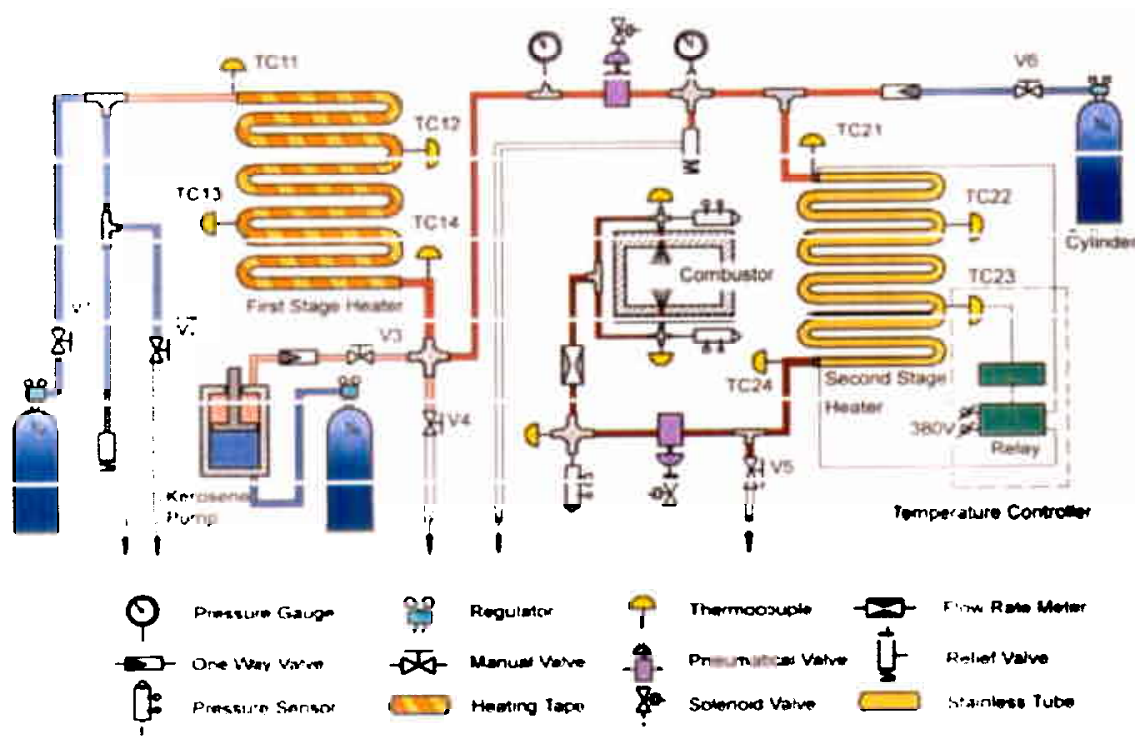

Figure 2 Schematic of kerosene delivery and heating system.

Kerosene Delivery and Heating System

A major concern in fuel heating system is how to prevent the carbon formation, particularly due to pyrolytic cracking ${ }^{[2]}$. The rate of this fuel coking is generally proportional exponentially to temperature and linearly to the residence time ${ }^{22}$. To minimize the fuel coking at high temperature, a two-stage electrical resistance heating system has been designed as shown in Fig. 2. The first stage is a storage type heater which can heat $0.8 \mathrm{~kg}$ of kerosene up to $570 \mathrm{~K}$ with minor/negligible coking deposit, while the second stage is a continuous one which can heat kerosene up to $830 \mathrm{~K}$. The residence time of vaporized kerosene within the second heater is less than 2 seconds, thereby minimizing the extent of fuel coking.

Furthermore, the first-stage heater consisted of a twenty-meter long stainless steel tube of $20 \mathrm{~mm}$ inner diameter and $1.5 \mathrm{~mm}$ wall thickness, which was wound into a $30 \mathrm{~cm}$ diameter cylinder shape. The stainless steel tube was wrapped with five $960-\mathrm{W}$ heating tapes, which was controlled independently in order to achieve a uniform temperature distribution along the tube. On the other hand, the second-stage heater was directly heated with the application of 80-100 DC voltages from a pulsed AC/DC welder power supply of $250 \mathrm{KW}$. In addition, the second-stage heater and the fuel injector were connected b y $10 \mathrm{~mm}$ diameter tubes, which were also wrapped by heating tapes to reduce the heat lose and avoid kerosene condensation before reaching the injector.

Two pneumatic valves were employed to turn-on/off the two heaters promptly, as shown in Fig. 2. After each run, nitrogen was used to purge the residual kerosene inside the second-stage heater to eliminate carbon deposit accumulation. Two groups of K-type thermocouples, TC11-14 and TC21-24 in Fig. 2, were installed on the surface of or inside the heater tubes, and were used to monitor and achieve the feedback control of fuel temperature distribution along the heater. Figure 3 shows a photograph of the test facility along with the kerosene heating and delivery system.

In order to carry out accurate measurements of kerosene vapor flow rates, a sonic nozzle flow meter was designed and installed between the second-stage heater and the injector for real-time monitoring. The details of the flow meter design, calibration procedure, and surrogate fuel property calculations will be discussed in the following sections. 


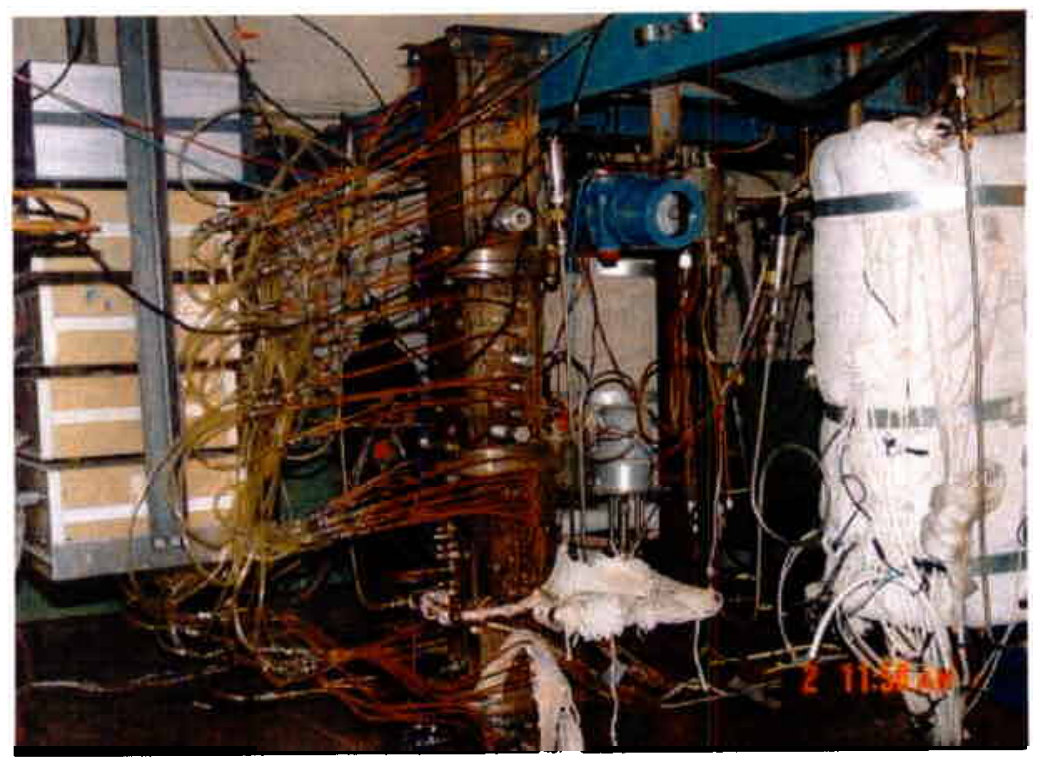

Figure 3 Photograph of test facility with the two-stage heater exchange system.

Table 1. Composition of China No.3 Aviation kerosene

\begin{tabular}{|c|c|c|c|c|c|c|c|c|c|c|}
\hline \multicolumn{5}{|c|}{ Saturated hydrocarbons } & \multicolumn{5}{|c|}{ Aromatic hydrocarbons } & Total \\
\hline \multirow[t]{2}{*}{ Alkanes } & \multicolumn{3}{|c|}{ Naphthenes } & \multirow[t]{2}{*}{ Total } & \multirow{2}{*}{$\begin{array}{c}\text { Alkyl } \\
\text { benzenes }\end{array}$} & \multirow{2}{*}{$\begin{array}{c}\text { Indan } \\
\& \\
\text { Tetralin }\end{array}$} & \multirow[t]{2}{*}{ Naphthalene } & \multirow{2}{*}{$\begin{array}{l}\text { Naphthalene } \\
\text { derivatives }\end{array}$} & \multirow[t]{2}{*}{ Total } & \\
\hline & Monocyclic & Bicyclic & Tricyclic & & & & & & & \\
\hline 52.2 & 33.8 & 6.0 & 0.1 & 92.1 & 5.1 & 1.3 & 0.6 & 0.9 & 7.9 & 100 \\
\hline
\end{tabular}

\section{Properties of Kerosene Fuel}

\section{Composition of Kerosene Surrogate}

Kerosene fuels are complex mixtures of alkanes, naphthenes, and aromatics. The China No.3 Aviation kerosene employed herein was approximately composed in volume of $92.5 \%$ saturated hydrocarbons, $0.5 \%$ unsaturated hydrocarbons, and $7 \%$ aromatic hydrocarbons. Table 1 shows the measured mass fractions of various components in the No.3 kerosene.

Recognizing that it is impossible to define a precise composition of the kerosene fuel, it is necessary to select a proper model composition to calculate various physical and chemical processes of kerosene, especially for simulation purposes. Ideally, this surrogate fuel is composed of a small number of pure hydrocarbons and has similar physical and chemical properties as those of a parent fuel.

Based on the consideration of matching the compound class in the No.3 kerosene fuel, a model fuel consisting in mole of $49 \% \mathrm{n}$-decane, $44 \%$ 1,3,5-trimethylcyclohexane, and $7 \%$ n-propyl- benzene, following the studies of Refs. [3, 4], has been used to calculate the representing thermodynamic and transport properties.

\section{Modeling of Kerosene Fuel}

As a coolant in scramjet operations at high Mach number, the liquid kerosene may heat up to/above the critical temperature. The fuel behavior in this region, however, is complex and very sensitive to the pressure and temperature. No single equation of states is available to fully represent the properties of the fuel over the entire range of temperature and pressure. Instead, the extended corresponding states (ECS) principle ${ }^{[5,6]}$ can be used. The corresponding states principle assumes that the equations of states when presented in terms of the reduced variables (normalized by the corresponding critical value) for various fluids follow exactly the same pattern and can be represented by those of a single reference fluid. Since only few fluids follow this corresponding states principle very accurately, the extended corresponding states principle adds one 
more parameter called "acentric factor" to account for the deviation of molecular shape from sphere and the effect of molecular dipole moment. The calculation was carried out with the aid of NIST SUPERTRAPP software package, in which the Benedict-Webb-Rubin (BWR) equation of states is used to evaluate the properties of various reference pure hydrocarbons.

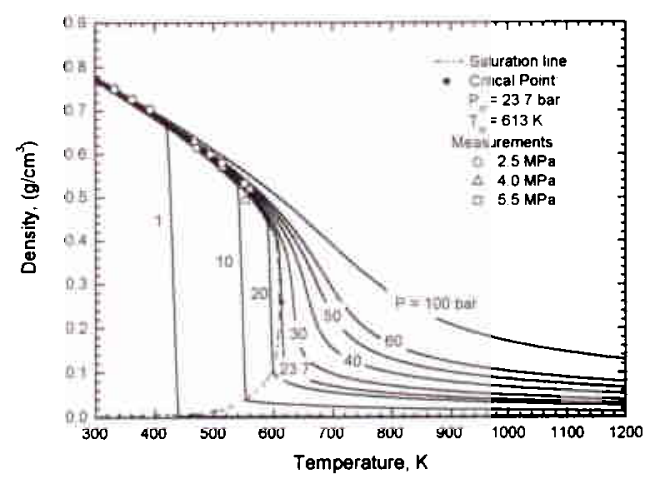

Figure $4 \rho-T$ isobar of the model fuel

Figure 4 shows the $\rho-T$ isobar of the present surrogate fuel calculated with SUPERTRAPP. The measured kerosene densities at low temperature range that we reported earlier ${ }^{[7]}$ are also plotted in Fig. 4 for comparison. It is seen that the computed results agree well with the experimental data at low temperature. We further note that the data at temperature higher than the coking/decomposition limit $(>800 \mathrm{~K})$ are included only for illustration purpose, and are not considered to be realistic in practical applications. The calculated critical pressure and temperature for the model fuel are 23.7 bar and $613 \mathrm{~K}$, respectively. When the fuel is in the supercritical regime, i.e., at a pressure exceeding the critical pressure, the latent heat is zero and the fuel can be transformed continuously from a liquid to a gas. In practical scramjet operation, the pressure and temperature of kerosene may fall into the critical region. To avoid the complexity with the possible occurrence of two-phase flow during transition, operation conditions with fuel pressure and temperature well above the critical point but temperature lower than the coking limit are preferred. In addition, the smooth transformation at supercritical pressure will ensure stable fuel delivery and facilitate the mass flow rate measurements.

Calculations also show that, in the critical region the speed of sound, viscosity, and thermal conductivity of the surrogate fuel decrease to the corresponding level of gas phase, while its heat capacity and specific heats increase dramatically..

\section{Flow Rate Calibration of Kerosene Vapor}

In the previous experiments ${ }^{[7]}$, the mass flow rate of liquid kerosene was determined with an orifice flow meter, which was calibrated by the actual amount of kerosene released divided by the time elapsed. Figure 5 shows the linear dependence of kerosene mass flow rate with the square root of the differential pressure at room temperature ${ }^{[7]}$.

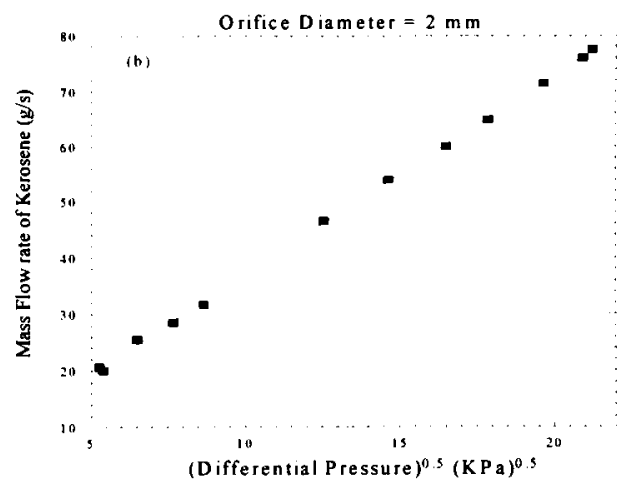

Figure 5 Calibration of liquid kerosene mass flow rate with an orifice plat flow meter.

For heated kerosene at temperature close to the critical point, the flow rate measurement using an orifice flow meter becomes somewhat complicated because the thermophysical properties of hot kerosene change rapidly with pressure and temperature. Instead, sonic nozzle flow meter can be used as long as the sonic condition at the throat is maintained.

Applying the assumption of isentropic acceleration, the properties at sonic condition corresponding to each stagnation temperature and pressure can be calculated with the aid of SUPERTRAPP. Figure 6 shows the calculated critical to total pressure ratio required to reach the sonic state for the kerosene surrogate; while Fig. 7 plots its mass flow rate per unit throat area.

Experimentally, the flow rate calibration of kerosene vapor is similar to the above-mentioned method for the liquid kerosene. However, a vapor collecting system is instrumental in the success of accurate calibration, which was accomplished by using the condenser of an air-conditioner. The measured flow rates per unit throat area at total pressures of 30, 38, and $46 \mathrm{~atm}$ are shown in Fig. 7, which are denoted as symbols. It is seen from Fig. 7 that the theoretical calculations using the model 
fuel are in good agreement with the measurements for temperature below $750 \mathrm{~K}$, while relative larger discrepancy near the critical region is noted. Experiments also showed that, when the fuel temperature was above $830 \mathrm{~K}$, coking became very severe and much less liquid kerosene could be collected. For temperature between 750 and $830 \mathrm{~K}$, the partial cracking of kerosene could lead to the deviation of prediction from the experimental data. Therefore, to accurately model the flow rate at temperature above $750 \mathrm{~K}$, the major products due to pyrolysis need to be taken into account.

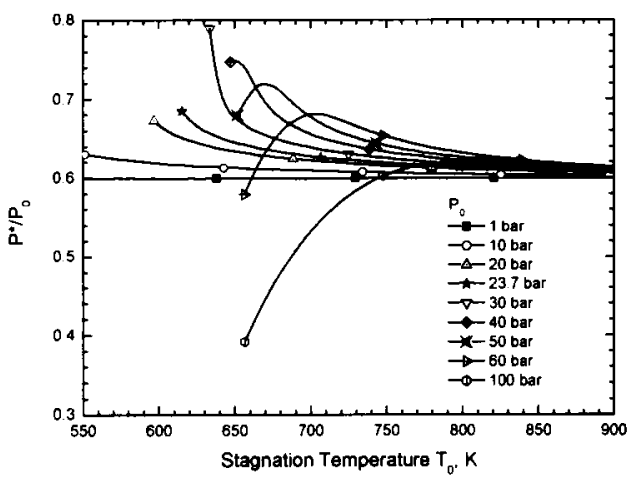

Figure 6 Profiles of critical pressure ratio of surrogate fuel vapor as a function of stagnation temperature.

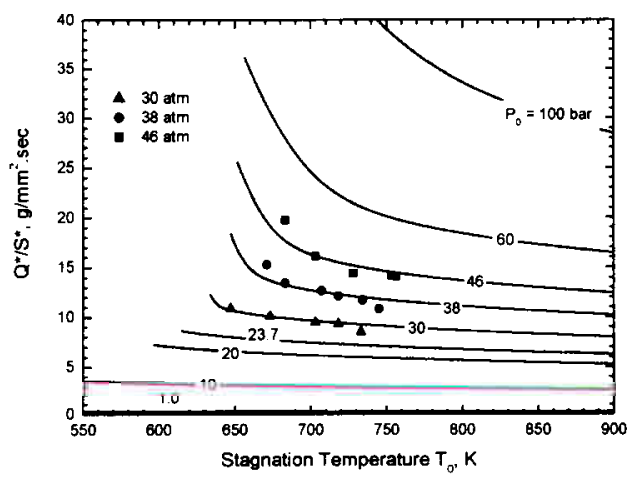

Figure 7 Comparison of experimental computational mass flow rates of kerosene vapor.

\section{Results and Discussion}

Characterization of Heated Kerosene Jet into Quiescent Atmosphere

With a given injection pressure of $4 \mathrm{MPa}$, Fig. 8 compares the direct images of four kerosene jets into quiescent atmosphere at injection temperatures of $290,480,510$, and $550 \mathrm{~K}$, respectively. The orifice diameter of injector was $0.8 \mathrm{~mm}$. It is seen that the heated kerosene jet first exhibited mixed liquid/vapor plume at injection temperature of $480 \mathrm{~K}$, as shown in Fig. 8(b). However, at this condition the amount of kerosene vapor was much smaller than that of liquid phase. Further increasing the injection temperature to $510 \mathrm{~K}$, Fig. 8(c) illustrates that vaporized kerosene dominates the jet structure, while little amount of liquid kerosene spray was still noted. Figure $8(\mathrm{~d})$ clearly shows that the heated kerosene completely turns into vapor phase at $550 \mathrm{~K}$ injection temperature. Especially, "white smoke" was observed even right at the injector exit. We note that the critical conditions of common kerosene are approximately $630 \mathrm{~K}$ and $22 \mathrm{~atm}$ (the calculated critical values of the present surrogate are $613 \mathrm{~K}$ and $23.4 \mathrm{~atm}$ ) and the background conditions of Fig. 8 are much lower than their critical values. As a result, the hot high-pressure supercritical kerosene would experience sudden vaporization at the injector exit as the pressure drops to atmospheric level. Subsequently, the fuel vapor condenses into liquid droplets as its temperature drops. The increase in plume angle with increasing injection temperature, as shown in Fig. 8, is a result of enhanced vaporization, which in turn promotes the overall kerosene-air mixing.

Characterization of Heated Kerosene Jet into a Supersonic Crossflow

Four kerosene jets with the same conditions as those of Fig. 8 were visualized by injecting into a Mach 2.5 crossflow, with local static conditions of $570 \mathrm{~K}$ and $0.07 \mathrm{MPa}$. Again, the orifice diameter of injector was $0.8 \mathrm{~mm}$. Figure 9 shows the corresponding Schlieren images. It is seen that the heated kerosene jet structure was severely bent by the Mach 2.5 crossflow and the bow shock ahead of the jet was evident. It is also of interest to note that the penetration depth of four kerosene jets was approximately the same in the temperature range of 290-550 K, implying the resulting jet momentums were quite similar as a consequence of the same applied total pressure.

For the case of pure liquid atomization shown in Fig. 9(a), the spray structure in the Schlieren image appears to be dark owing to the blockage of 

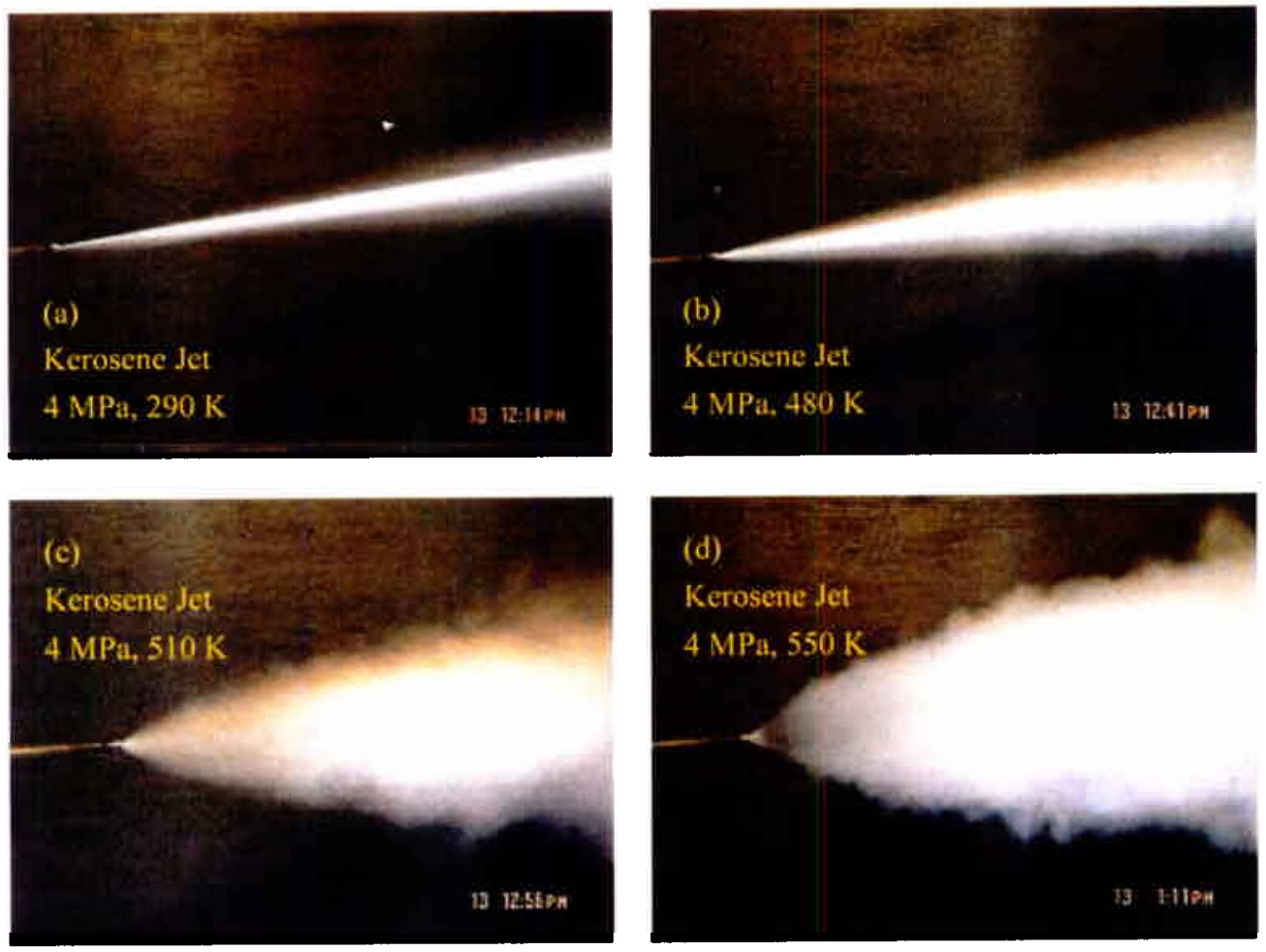

Figure 8 Direct images of pressurized kerosene jet into quiescent atmosphere at different injection temperatures.

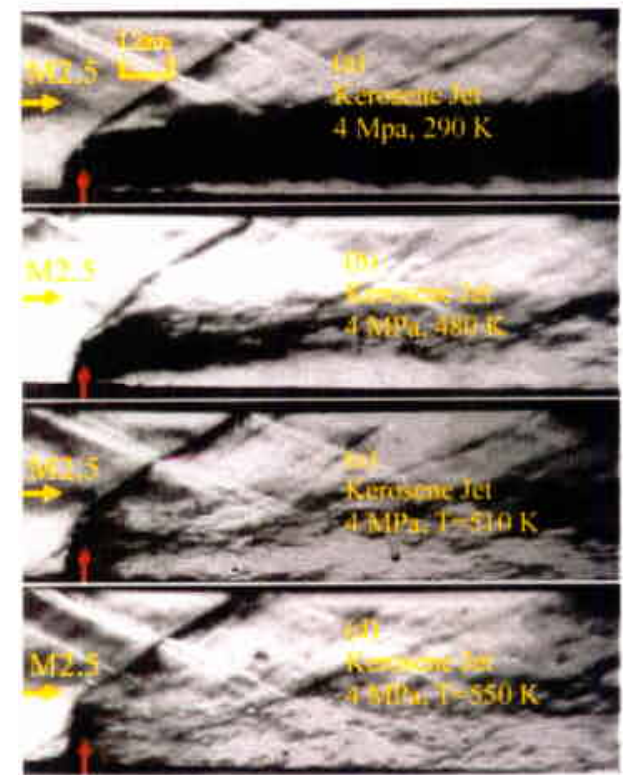

Figure 9. Schlieren images of pressurized kerosene jet into a Mach 2.5 crossflow at different injection temperatures. The local static conditions are of $570 \mathrm{~K}$ and $0.07 \mathrm{MPa}$.

incident light by the fine droplets. As the temperature of $k$ erosene is increased to $480 \mathrm{~K}$, the blockage of incident light by kerosene spray, while still noticeable, is substantially reduced, as seen in Fig. 9(b). Further increasing kerosene temperature beyond $500 \mathrm{~K}$, Figs. 9(c)-(d) clearly show that the heated kerosene jet structures become more and more transparent to the incident light. Obviously, this transparency is indicative of the greater extent of kerosene gasification. The level of fuel-air mixing is also expected to be enhanced with increasing injection temperature. The present results demonstrate that it is feasible to achieve complete vaporization of kerosene and to inject the vaporized kerosene into a supersonic combustor with comparable penetration depth as the liquid jet. Since the use of vaporized kerosene bypasses the vaporization process, the performance of a supersonic combustor is expected to be improved.

\section{Effects of Vaporized Fuel Injection on Combustion} performance

A series of experiments were then carried out in a Mach 2.5 model combustor with vaporized kerosene injection under approximately identical flow conditions, i.e. a stagnation temperature of $1750 \mathrm{~K}$ and a stagnation pressure of $1.18 \mathrm{MPa}$. It is 
noted that the kerosene fuel prior to injection was preheated under supercritical pressure to a supercritical temperature. The preheat temperature of kerosene is comparable to the local static temperature in the combustor.

Figure 10 demonstrates the performance of the two-stage heating system by plotting the time variations of temperatures at the exits of two heaters. It is seen from Fig. 10 that the temperature profile at the exit of the second-stage heater levels off in two seconds after the starting of run. Hence, the injection temperature of pressurized kerosene can be kept constant during the experiment duration.

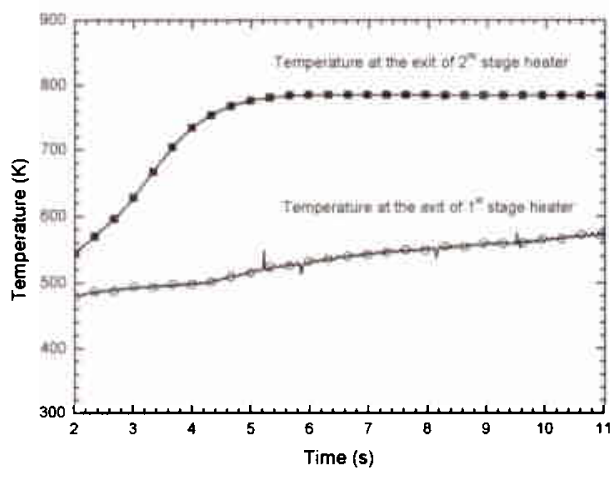

Figure 10 Typical kerosene temperature histories measured at the exits of two heaters.

A comparison of the measured static pressure distributions within the supersonic model combustor for the cases with vaporized and liquid kerosene injections at the global equivalent ratio $\phi_{\mathrm{f}}$ of $0.37-0.38$ is shown in Fig. 11. The kerosene vapor was injected at temperature of $700-750 \mathrm{~K}$ and pressures of 3.8 $\mathrm{MPa}$. The data for liquid kerosene injection at room temperature was taken from our early studies [8]. A significant improvement in the static pressure distribution can be seen from Fig. 11 with vapor injection over liquid kerosene injection. In addition, Fig. 11 demonstrates that the experimental data for the cases with vaporized kerosene injection are highly repeatable within the uncertainty of the experiment.

The performance characteristics of supersonic combustion using vaporized kerosene injection were further compared to those obtained using effervescent atomization with hydrogen barbotage ${ }^{[\mathrm{f}]}$ Figure 12 compares the static pressure distributions for the experiments with vaporized kerosene injection and effervescent atomization with $2.5 \%$ hydrogen barbotage, at the global equivalent ratio $\phi_{\mathrm{f}}$ of 0.44-0.45. The kerosene vapor was injected at temperature of $700-750 \mathrm{~K}$ and pressure of $4.6 \mathrm{MPa}$. It was found that the static pressure increase during combustion is larger for the cases with vaporized kerosene injection.

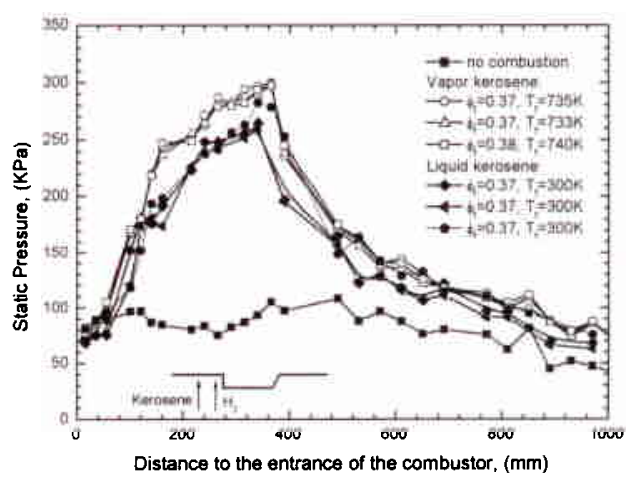

Figure 11 Comparison of static pressure distributions with vaporized and liquid kerosene injections. Vitiated Mach 2.5 Air: $P_{0}=1.06-1.20 \mathrm{MPa}$ and $T_{0}=1750-1850 \mathrm{~K}$.

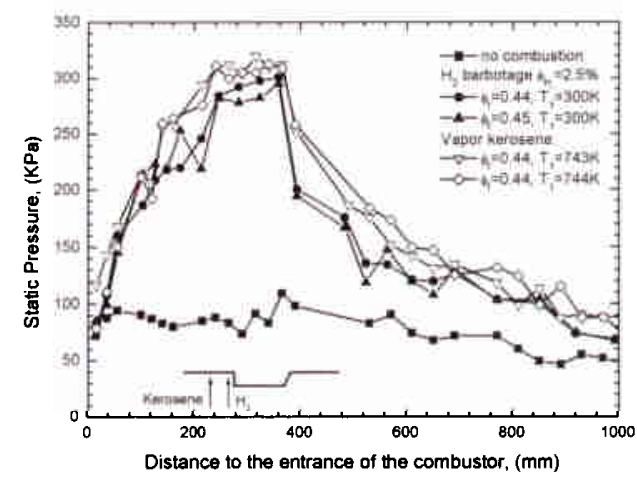

Figure 12 Comparison of static pressure distributions for the cases using vaporized kerosene injection and effervescent atomization with hydrogen barbotage. Vitiated Mach 2.5 air: $P_{0}=1.06-1.18 \mathrm{MPa}$ and $T_{0}=1700$ 1790K.

Since the increase in the adiabatic flame temperature due to fuel preheating is not significant, the improvements in combustor performance when using vaporized kerosene injection could be twofold. First, the elimination of the vaporization process shortens the time for self-ignition, thereby promoting overall burning intensity. Second, the changes in the physical properties of kerosene leads to mixing enhanceinent, as demonstrated in Figs. 8 and 9. 


\section{Summary}

Characteristics of kerosene combustion in a Mach 2.5 model combustor using vaporized kerosene injection at various preheat temperatures and pressures were experimentally investigated. A two-stage heating system with minimum fuel coking has been designed and tested. The present system can prepare kerosene vapor of $0.8 \mathrm{~kg}$ up to $820 \mathrm{~K}$ at pressure up to $5.5 \mathrm{MPa}$. A three-species surrogate was selected to simulate the thermophysical properties of the China No.3 kerosene using NIST SUPERTRAPP code, over the ranges of pressure and temperature relevant to the experimental conditions. The flow rate calibration of kerosene vapor using a sonic nozzle agrees well with the theoretical predictions based on the surrogate fuel. Schlieren visualizations demonstrate that the kerosene jet was completely in vapor phase at injection pressure of 4 $\mathrm{MPa}$ and temperature of $550 \mathrm{~K}$, while keeping the penetration depth essentially unchanged. Combustion tests also showed that the static pressure profiles for the cases with vaporized kerosene injection are significantly higher than those of with liquid kerosene injection, and even higher than those of effervescent atomization with hydrogen barbotage. These results demonstrated that the performance of the supersonic model combustor indeed improved remarkably with the injection of fuel vapor. Detailed studies are therefore needed to understand the physical and chemical processes involving vaporized kerosene injection in a supersonic model combustor.

\section{Acknowledgements}

Current research program was supported by the National Natural Science Foundation of China under contractor 10232060 . The authors would like to acknowledge Prof. X. N. Lu for the assistance in designing and testing the kerosene heater. We also thank Mr. D. X. Qian and Mr. Y. Li for the technical support.

\section{References}

1. Yu, G, Li, J.G., Yang, S.R., Yue, L.J., Chang, X.Y., Huang, Y., and Sung, C.J., "Characteristics of Kerosene Combustion in Supersonic Flow Using Effervescent Atomization," AlAA Paper 2002-5225, 2002.

2. Edwards, T, "Liquid Fuel and Propellant for Aerospace Propulsion: 1903-2003," Journal of Propulsion and Power, Vol.19, No. 6, November-December 2003.

3. Daniau, E., etc., "Contribution to Scramjet Active Cooling Analysis Using N-Dodecane
Decomposition Model as a Generic Endothermic Fuel," AIAA Paper 2003-6920, 2003.

4. Dagaut, P., "On the Kinetics of Hydrocarbon Oxidation from Natural Gas to Kerosene and Diesel Fuel," Phys. Chem. Chem. Phys., 2002, 4, 2079-2094.

5. Fisher, G. D., and Leland, T. W., "The Corresponding States Principle Using Shape Factors," Ind. Eng. Chem. Fundamentals, 9, 537-544, 1970.

6. Yang, V., "Modeling of Supercritical Vaporization, Mixing and Combustion Processes in Liquid-fueled Propulsion System", Proceeding of the Combustion Institute, Vol.28, 2000, 925-942.

7. G. Yu, J. G. Li, Z. Zhao, X. Y. Chang and C. J. Sung, "Investigation of Vaporized Kerosene Injection in a Supersonic Model Combustor," AIAA paper 2003-6938, Norfolk, Virginia, December 15 - 19, 2003

8. Yu, G., Li, J.G., Chang, X.Y., Chen, L.H., and Sung, C.J., "Fuel Injection and Flame Stabilization in a Liquid-Kerosene-Fueled Supersonic Combustor," Journal of Propulsion and Power, Vol. 19, No. 5, 2003, pp. 885-893. 